Article

\title{
Revisiting the Taxonomic Synonyms and Populations of Saccharomyces cerevisiae-Phylogeny, Phenotypes, Ecology and Domestication
}

\author{
Ana Pontes ${ }^{1}\left[\right.$, Mathias Hutzler ${ }^{2} \mathbb{(}$, Patrícia H. Brito ${ }^{1}\left[\right.$ and José Paulo Sampaio ${ }^{1, *(\mathbb{C}}$ \\ 1 UCIBIO, Departamento de Ciências da Vida, Faculdade de Ciências e Tecnologia, Universidade Nova de \\ Lisboa, 2829-516 Caparica, Portugal; ap.pontes@fct.unl.pt (A.P.); phbrito@fct.unl.pt (P.H.B.) \\ 2 Research Center Weihenstephan for Brewing and Food Quality, TU München, D-85354 Freising, Germany; \\ m.hutzler@tum.de \\ * Correspondence: jss@fct.unl.pt; Tel.: +351-21-294-8530
}

Received: 23 May 2020; Accepted: 9 June 2020; Published: 15 June 2020

\begin{abstract}
Saccharomyces cerevisiae - the most emblematic and industrially relevant yeast-has a long list of taxonomical synonyms. Formerly considered as distinct species, some of the synonyms represent variants with important industrial implications, like Saccharomyces boulardii or Saccharomyces diastaticus, but with an unclear status, especially among the fermentation industry, the biotechnology community and biologists not informed on taxonomic matters. Here, we use genomics to investigate a group of 45 reference strains (type strains) of former Saccharomyces species that are currently regarded as conspecific with $S$. cerevisiae. We show that these variants are distributed across the phylogenetic spectrum of domesticated lineages of $S$. cerevisiae, with emphasis on the most relevant technological groups, but absent in wild lineages. We analyzed the phylogeny of a representative and well-balanced dataset of S. cerevisiae genomes that deepened our current ecological and biogeographic assessment of wild populations and allowed the distinction, among wild populations, of those associated with low- or high-sugar natural environments. Some wild lineages from China were merged with wild lineages from other regions in Asia and in the New World, thus giving more resolution to the current model of expansion from Asia to the rest of the world. We reassessed several key domestication markers among the different domesticated populations. In some cases, we could trace their origin to wild reservoirs, while in other cases gene inactivation associated with domestication was also found in wild populations, thus suggesting that natural adaptation to sugar-rich environments predated domestication.
\end{abstract}

Keywords: Saccharomyces cerevisiae; Saccharomyces boulardii; Saccharomyces diastaticus; population genomics; yeast domestication; STA1; MEL1

\section{Introduction}

Saccharomyces cerevisiae - the most emblematic and industrially relevant yeast species-was defined in 1838 by Meyen [1] and typified, i.e., linked to a living type strain, by Hansen in 1883. In the following decades, physiological and morphologic characters were the sole criteria available to yeast taxonomists and even minor phenotypic differences were considered adequate for species delimitations, a practice that promoted a continuous rise in the number of accepted species. As a consequence, Stelling-Dekker in 1931 [2], Lodder and Kreger-van Rij in 1952 [3] and van der Walt in 1970 [4] recognized 23, 30 and 41 Saccharomyces species, respectively. As in other microbial groups, yeast classification based on phenotypic markers was challenged when DNA based methods started to be implemented as taxonomic tools. As a result, numerous Saccharomyces species were recognized as synonyms of 
S. cerevisiae [5] and a list of approximately 100 species or varietal names was merged into that species. Such taxonomical changes were continued in subsequent decades and generated an understandable confusion among scientists and industry professionals not versed in yeast systematics.

More recently, complete genome sequencing has provided the necessary resolution to dissect S. cerevisiae at the population level and various studies have revealed a complex scenario with wild, domesticated and admixed groups [6-9]. Here, we use genomics to investigate a group of 45 reference strains (type strains) of former Saccharomyces species-currently regarded as synonyms of S. cerevisiae - many of which represent strains isolated from human-made fermentations worldwide. We show that these variants are distributed across the phylogenetic spectrum of domesticated lineages of $S$. cerevisiae, with a majority belonging to in the most relevant technological groups, but totally absent in wild lineages. We also examine salient features of domesticated lineages and reassess the biogeography and ecology of wild lineages.

\section{Materials and Methods}

\subsection{Genome Sequencing, Read Alignment and Genotype Calling}

Paired-end Illumina MiSeq (500 cycles) or NextSeq (300 cycles) reads were obtained for 37 strains. Genomic data for other strains were retrieved from public databases as indicated in Table S1. When only finished genome sequences were available, the corresponding error-free Illumina reads were simulated using DWGSIM.

Reads for each isolate were mapped to an extended Saccharomyces spp. reference containing sequences of S. cerevisiae (UCSC version sacCer3), S. paradoxus, S. mikatae, S. kudriavzevii, S. uvarum [10] and S. arboricolus [11], as previously described by [12] and using SMALT v. 0.7.5 aligner. The reference Index was built with a word length of 13 and a sampling step size of 2 (-k 13 -s 2). An intensive search for alignments $(-x)$ was performed during the mapping step with the random assignment of ambiguous alignments switched off $(-r-1)$ and the base quality threshold for the look-up of the hash index set to 10 (-q 10). With these settings, SMALT v. 0.7.5 only reports the best unique gapped alignment for each read. The insert size distribution was inferred with the 'sample' command of SMALT prior to mapping. Conversion of SAM format to BAM, sorting, indexing, several mapping statistics and consensus genotype calling were performed using the tools available in the SAMtools package v. 1.18 [13] and as described previously [14]. Multiple sequence alignments for each reference chromosome were generated from the resulting FASTA files. For downstream analysis, all bases with a Phred quality score below Q40 (equivalent to a $99.99 \%$ base call accuracy) or ambiguous base calls were converted to ' $\mathrm{N}$ '.

\subsection{Phylogenetic Analyses and Survey of Specific Genes}

For the construction of the main phylogeny, if contributions from non-S. cerevisiae species were detected, only the $S$. cerevisiae subgenome was considered. Chromosomal single-nucleotide polymorphisms (SNPs) were extracted from a multiple sequence alignment only if the SNP was present unambiguously in at least $85 \%$ of the strains in the alignment. SNPs were then concatenated to generate a whole genome SNP alignment. Strains with more than 20,000 heterozygous sites with a Phred quality score above Q40 were selected for phasing. The BAM file of each strain with the paired-end read sequences mapped to the reference genome was analyzed with the phase command of SAMtools to infer both phases, thus solving the heterozygous SNPs. The -F option was used to exclude errors from unmapped or misaligned sequences. One haplotype per strain was randomly chosen and used in subsequent analyses. The main phylogeny was inferred using the maximum likelihood method as implemented in IQ-TREE v. 1.6.11 [15], using the TVM+F+ASC+G4 model of sequence evolution and the ultrafast bootstrap approximation with 1000 replicates [16]. The software iTOL v. 3.0 [17] was used for visualization. Single gene phylogenies were constructed with MEGA 7 [18], using the Tamura 3-parameter model and the maximum-likelihood method. 
For the study of specific genes, whole genome assemblies were prepared with SPAdes v. 3.13.1. Prior to assembly, reads were processed with trimmomatic v. 0.36 to remove adapter sequences. In order to retrieve genes of interest, a local blast database was set for each genome and ORFS were searched with BLASTn using as queries: AQY1 and AQY2 of YPS163 [19], regions A, B and C of EC1118 [20], RTM1, BIO1 and BIO6 of CEN.PK13 [21], MEL1 of UWOPS 03-461.4 and UWOPS 91-917.1 [22] and STA1 [23]. Gene copy number was estimated by mapping the reads from each strain against the genome of strain UWOPS 03-461.4 [24], as described above. The median genome coverage was estimated as the coverage of each nuclear chromosome. Following a previous study [9], the ratio between the median coverage of each individual gene and the values of the genome coverage was considered a good estimate of the gene copy number.

\subsection{Phenotypic Analyses}

Strains investigated for the diastase phenotype were precultured in $20 \mathrm{~mL}$ of YPD $(1 \%(w / v)$ yeast extract, $2 \%(w / v)$ peptone, $2 \%(w / v)$ dextrose) overnight at $25{ }^{\circ} \mathrm{C}$. Washed cells were then inoculated in $50 \mathrm{~mL}$ of beer wort $\left(11^{\circ}\right.$ Brix $)$ and incubated for 15 days at $25^{\circ} \mathrm{C}$. The decrease of the ${ }^{\circ}$ Brix was monitored and strains that in the end of the incubation period had $a{ }^{\circ}$ Brix lower than 4 were considered positive for the diastase phenotype. Strains investigated for the ability to grow on melibiose were precultured in $200 \mu \mathrm{L}$ of $0.2 \%(w / v)$ glucose and YNB (yeast nitrogen base, Difco) in a 96-well plate overnight at $25^{\circ} \mathrm{C}$. Then, $10 \mu \mathrm{L}$ were inoculated $200 \mu \mathrm{L}$ of $1 \%(w / v)$ melibiose and YNB. Growth was followed by measuring absorbance at $640 \mathrm{~nm}$ for three days in a Tecan Spark (Tecan Trading, Männedorf, Switzerland) microplate reader incubated at $25^{\circ} \mathrm{C}$.

\section{Results}

\subsection{Global Phylogenetic Analysis Reveals an Unequal Distribution of Type Strains of Former Species}

We analyzed the genomes of 45 strains considered in the past as distinct Saccharomyces species (or varieties), but now regarded as S. cerevisiae synonyms, together with the valid type strain of S. cerevisiae (Table 1) and an additional 202 genomes representing the population diversity and technological variants currently known (Table S1). This is the most comprehensive dataset representing the diversity in this species. The phylogenetic analysis of these 247 genomes is shown in Figure 1 and a simplified unrooted phylogeny is shown in Figure S1. We identified 27 clades that represent the various technological variants of $S$. cerevisiae or geographical or ecological populations, many of which have been recognized previously by us or by other authors. In order to contribute to standardizing the designations of populations of $S$. cerevisiae, we provide a list of designations used here and a comparison with designations employed in other studies in Table 2. We also classified the 27 clades according to their association with domesticate or wild populations (Figure 1 and Table 2). In the first case the strains are associated with processes like wine or beer fermentations and are expected to have acquired specific domestication signatures. In the second case the populations have an ecological or geographic circumscription, like for example the Mediterranean oaks population.

Except for PYCC 4654, the type strain of S. fructuum, that occupies an isolated position in the phylogeny outside any of the recognized clades, all other type strains formed clades with technological, and therefore domesticated groups, namely the Wine (two clades), Olives, Beer (two clades), Bread, Dairy, Sake and West African groups (Figure 1). Therefore, the distribution of type strains of former species is markedly unbalanced across the spectrum of genetic diversity of $S$. cerevisiae. The Wine and Olives groups congregated most (29 out of 45 ) of the type strains analyzed, followed by the two beer groups that together gathered seven type strains, including the recognized type strain of S. cerevisiae (PYCC 4455), a beer strain assigned to the Beer 1 clade. Overall, nine of the 27 clades that represent distinct populations of $S$. cerevisiae, included at least one type strain. Remarkably, all the wild populations like those found in arboreal niches in China, Europe or the Americas did not include any of 
the type strains of former species. A more detailed analysis of the distribution of former Saccharomyces type strains in the context of the groups to which they were assigned is presented below.

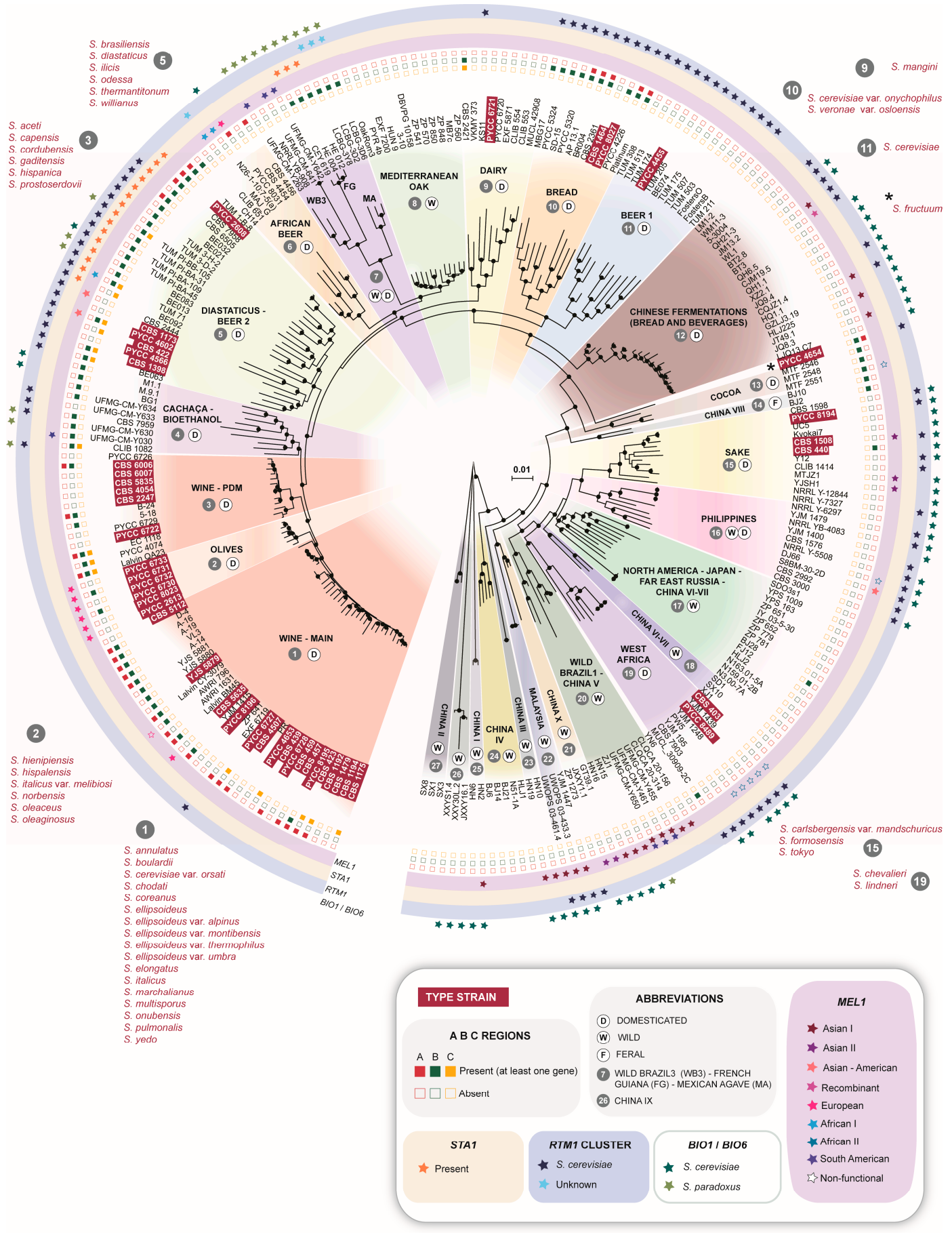

Figure 1. Current synonyms of $S$. cerevisiae are unequally distributed among the known lineages of the species. The phylogeny was inferred from 248 sequences and 1,520,302 single nucleotide polymorphisms using the TVM+F+ASC $+\mathrm{G} 4$ model of sequence evolution and the maximum likelihood method as implemented in IQ-TREE and was rooted with S. paradoxus. Branch lengths correspond to the expected number of substitutions per site and black dots in tree nodes depict bootstrap support values above $95 \%$ (1000 replicates). The 27 clades detected are numbered in gray circles, the former type strains of current synonyms of $S$. cerevisiae are highlighted in red rectangles. 
Table 1. Synonyms of Saccharomyces cerevisiae analyzed in this study and relevant information pertaining to them (the type strain of S. cerevisiae is also included).

\begin{tabular}{|c|c|c|c|c|c|c|}
\hline Original Name & Strain Number ${ }^{\#}$ & Strain Number (Other Collections) & Strain Status & Population & Substrate of Isolation & Locality of Isolation \\
\hline Saccharomyces aceti Santa María 1958 & $\begin{array}{l}\text { CBS } 4054 \\
\text { PYCC } 6727\end{array}$ & 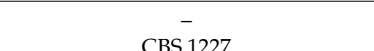 & type strain & WINE-PDM & $\begin{array}{l}\text { red wine } \\
\end{array}$ & $\begin{array}{c}\text { Spain } \\
\text { Spaind }\end{array}$ \\
\hline Saccharomyces annulatus Negroni 1929 & PYCC 6727 & CBS 1227 & type strain & WINE-MAIN & abscess on epididymis & New Zealand \\
\hline $\begin{array}{c}\text { Saccharomyces boulardii Seguela, Bastide \& Massot } 1984 \\
\text { (invalid name) }\end{array}$ & YJS 5879 & - & type strain & WINE-MAIN & lychee & Vietnam \\
\hline $\begin{array}{l}\text { Saccharomyces brasiliensis Lindner 1909; Saccharomyces logos } \\
\text { van Laer ex Jörgenssen } 1909\end{array}$ & PYCC 4602 & CBS 382 & type strain & BEER 2- DIASTATICUS & beer (Logos brewery) & Rio de Janeiro, Brazil \\
\hline Saccharomyces capensis van der Walt \& Tscheuschner 1956 & CBS 2247 & - & type strain & WINE-PDM & grape must & South Africa \\
\hline Saccharomyces cerevisiae Meyen ex Hansen 1883 & PYCC 4455 & CBS 1171 & neotype strain & BEER 1 & brewer's top yeast & $\begin{array}{l}\text { Oranjeboom brewery, } \\
\text { Rotterdam, Netherlands }\end{array}$ \\
\hline 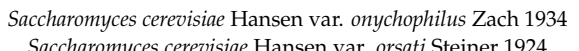 & CBS 1464 & - & type strain & BREAD & nail of 4-year-old girl & Austria \\
\hline Saccharomyces cerevisiae Hansen var. orsati Steiner 1924 & CBS 1175 & - & type strain & WINE-MAIN & wine 0 & unknown \\
\hline Saccharomyces chevalieri Guilliermond 1914 & PYCC 8489 & NRRL Y-12,633; CBS 400 & type strain & WEST AFRICA & palm wine from Elaeis guineensis & Ivory Coast \\
\hline Saccharomyces chodati Steiner 1924 & CBS 423 & - & type strain & WINE-MAIN & wine & Switzerland \\
\hline Saccharomyces cordubensis Santa María 1970 & CBS 6007 & - & type strain & WINE-PDM & wine & Spain \\
\hline Saccharomyces coreanus Saito 1910 & CBS 5635 & - & neotype strain & WINE-MAIN & grape must & South Africa \\
\hline $\begin{array}{l}\text { Saccharomyces diastaticus Andrews \& Gilliland ex van der } \\
\text { Walt } 1965\end{array}$ & PYCC 2608 & CBS 1782 & type strain & BEER 2-DIASTATICUS & super-attenuated beer & unknown \\
\hline $\begin{array}{l}\text { Saccharomyces carlsbergensis Hansen var. mandschuricus } \\
\text { (Saito) Stelling-Dekker } 1931\end{array}$ & CBS 1508 & - & type strain & SAKE & starter for sorghum brandy & unknown \\
\hline Saccharomyces ellipsoideus Reess 1870 & PYCC 4653 & CBS 1395; NRRL Y-1529 & neotype strain & WINE-MAIN & unknown & unknown \\
\hline Saccharomyces ellipsoideus Hansen var. umbra Castelli 1933 & CBS 457 & - & type strain & WINE-MAIN & grape must & Italy \\
\hline Saccharomyces ellipsoideus Hansen var. alpinus Steiner 1924 & CBS 1192 & - & type strain & WINE-MAIN & wine & unknown \\
\hline $\begin{array}{l}\text { Saccharomyces ellipsoideus Hansen var. montibensis } \\
\text { Steiner } 1924\end{array}$ & CBS 1479 & - & type strain & WINE-MAIN & wine & unknown \\
\hline $\begin{array}{l}\text { Saccharomyces ellipsoideus Hansen ssp. thermophilus } \\
\text { Steiner } 1924\end{array}$ & CBS 1194 & - & type strain & WINE-MAIN & wine & unknown \\
\hline Saccharomyces fructuum Lodder \& Kreger-van Rij 1952 & PYCC 4654 & CBS 1544 & type strain & OUTLIER & fermenting fruit juice & Netherlands \\
\hline Saccharomyces elongatus Krumbholz 1932 & CBS 439 & - & type strain & WINE-MAIN & Silvaner grapes & Germany \\
\hline Saccharomyces formosensis Nakazawa 1933 & CBS 440 & - & type strain & SAKE & molasses & Taiwan \\
\hline Sacharomyces gaditensis Santa María 1970 & CBS 6006 & - & type strain & WINE-PDM & wine & Spain \\
\hline Saccharomyces hienipiensis Santa María 1962 & PYCC 6733 & VKM Y-1235 & type strain & OLIVES & alpechin & Spain \\
\hline Saccharomyces hispalensis Santa María 1978 & PYCC 8023 & CBS 7002 & type strain & OLIVES & alpechin & Seville, Spain \\
\hline Saccharomyces hispanica Santa María 1968 & CBS 5835 & - & type strain & WINE-PDM & wine & Spain \\
\hline Saccharomyces ilicis Grönlund 1893 & CBS 1173 & - & type strain & OUTLIER & fruit of Ilex aquifolium & unknown \\
\hline Saccharomyces italicus Castelli 1939 & CBS 459 & - & type strain & WINE-MAIN & grape must & Italy \\
\hline $\begin{array}{l}\text { Saccharomyces italicus var. melibiosi van Uden } \\
\text { \& Assis-Lopes } 1957\end{array}$ & PYCC 2613 & CBS 2909 & type strain & OLIVES & feces of man & Portugal \\
\hline Saccharomyces lindneri Guilliermond 1914 & CBS 403 & PYCC 4571 & type strain & WEST AFRICA & ginger beer from Zinziber officinale & West Africa \\
\hline Saccharomyces mangini var. casei Saccchetti 1933 & PYCC 6721 & CBS 420; VKM Y-482 & type strain & DAIRY & stracchino cheese & Italy \\
\hline Saccharomyces marchalianus Kufferath 1920 & PYCC 8196 & CBS 1460 & type strain & WINE-MAIN & fermenting fruit & Indonesia \\
\hline Saccharomyces multisporus Jörgensen 1909 & CBS 4507 & 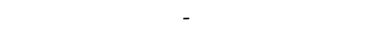 & type strain & WINE-MAIN & English top brewing yeast & unknown \\
\hline
\end{tabular}


Table 2. Populations of S. cerevisiae and their designations.

\begin{tabular}{|c|c|c|c|c|}
\hline Population & Designation in Other Studies & $\begin{array}{l}\text { Life Style } \\
\text { (W-Wild; D-Domesticated; F-Feral) }\end{array}$ & $\begin{array}{l}\text { Number of Type Strains of Former } \\
\text { Saccharomyces Species }\end{array}$ & Comments \\
\hline 1-Wine-main & Wine [25]; Wine/European [6,9] & $\mathrm{D}$ & 17 & $\begin{array}{l}\text { Global distribution probably associated with the widespread dissemination of } \\
\text { winemaking }\end{array}$ \\
\hline 2-Olives & Alpechin [9]; Olives [26,27] & $\mathrm{D}$ & 6 & Ancestral hybrids with S. paradoxus associated with processed olives \\
\hline 3-Wine-PDM & $\begin{array}{l}\text { Flor [25,28]; Georgian [9]; PDM-Prise de } \\
\text { Mousse [12]; }\end{array}$ & D & 6 & $\begin{array}{l}\text { Lalvin EC1118, a well-known commercial strain in this group is also known as } \\
\text { "Prise de mousse" or Champagne strain [20,28]. This population also contains } \\
\text { the Spanish flor yeasts of Xerez wine (Sherry) and similar wines [28] }\end{array}$ \\
\hline 4-Cachaça-Bioethanol & $\begin{array}{l}\text { Brazilian bioethanol [9]; Cachaça C1 and } \\
\text { C2 [29]; Rum and bioethanol [25] }\end{array}$ & $\mathrm{D}$ & - & $\begin{array}{l}\text { This group is a secondary domesticate derived from wine strains and includes } \\
\text { two types of cachaça strains (C1 and C2) and bioethanol strains [29] }\end{array}$ \\
\hline 5-Beer 2-Diastaticus & Beer 2 [30]; Mosaic beer [9] & D & 6 & $\begin{array}{l}\text { Contains Saison-type low-gravity beer strains and beer-spoilage strains with } \\
\text { diastase activity }\end{array}$ \\
\hline 6-African beer & African beer [9] & D & - & $\begin{array}{l}\text { Includes strains that ferment malted millet to produce bantu beer or malted } \\
\text { sorghum to produce bili-bili or kaffir beer }\end{array}$ \\
\hline $\begin{array}{l}\text { 7-Wild Brazil 3-French } \\
\text { Guiana-Mexican agave }\end{array}$ & $\begin{array}{l}\text { Mexican agave, French Guiana human } \\
\text { [9]; Wild Brazil B3 [31] }\end{array}$ & $\mathrm{W} / \mathrm{D}$ & - & $\begin{array}{l}\text { Complex clade composed of three subclades, one containing wild strains found } \\
\text { in Brazil, another containing strains used in artisanal mezcal fermentation in } \\
\text { Mexico and a third one containing gut-associated strains from French Guiana } \\
\text { aborigines; this last group contains STA1 and was also found in cachiri, a } \\
\text { traditional beer made from chewed and fermented starch-rich manioc [32] }\end{array}$ \\
\hline 8-Mediterranean oak & - & $\mathrm{W}$ & - & $\begin{array}{l}\text { Unique wild population with no evident links to the core group of Asian wild } \\
\text { populations; no changes in designation since the original description [8] }\end{array}$ \\
\hline 9-Dairy & Cheese [25]; French dairy [9]; Milk [33] & $\mathrm{D}$ & 1 & $\begin{array}{l}\text { Recently revealed population associated with dairy products and adapted to } \\
\text { galactose utilization }\end{array}$ \\
\hline $\begin{array}{l}\text { 10-Bread } \\
\text { 11-Beer } 1\end{array}$ & Active dry yeast [33]; Mixed [30] & $\mathrm{D}$ & 2 & \\
\hline $\begin{array}{l}\text { 11-Beer } 1 \\
\text { 12-Chinese fermentations } \\
\text { (bread and beverages) }\end{array}$ & $\begin{array}{c}\text { Ale beer [9]; Beer [25]; Beer } 1 \text { [30] } \\
\text { Mantou (bread)/Baijiu } \\
\text { (distilled)/Huangjiu (rice wine)/Qingkejiu }\end{array}$ & $\mathrm{D}$ & - & $\begin{array}{l}\text { Various sub-populations associated with different ale-beer types } \\
\text { Predominantly Chinese domesticated strains that are distinct from strains of } \\
\text { the Sake clade }\end{array}$ \\
\hline 13-Cocoa & $\begin{array}{l}\text { (barley wine)/frermented milk [33] } \\
\text { West African cocoa [9] }\end{array}$ & $\mathrm{D}$ & - & \\
\hline 14-China VIII & - & $\mathrm{F}$ & - & $\begin{array}{l}\text { Found in the arboreal niche in China, but with several domestication } \\
\text { signatures ( } M A L \text { gene expansion, } A Q Y \text { inactivation, presence of region B) }\end{array}$ \\
\hline 15-Sake & $\begin{array}{l}\text { Asia [27,30]; Asian fermentation, } \\
\text { Sake [6,9] }\end{array}$ & $\mathrm{D}$ & 3 & \\
\hline 16-Philippines & Asian islands [9]; Philippines [27] & W/D & - & \\
\hline $\begin{array}{l}\text { 17-North America-Japan-Far } \\
\text { East Russia-China VI-VII }\end{array}$ & $\begin{array}{c}\text { China VI-VII [33,34]; Far East Russia [9]; } \\
\text { North American [6] }\end{array}$ & w & - & A wild Chinese population also found in North America, Japan and Russia \\
\hline $\begin{array}{l}\text { East Russia-China VI-VII } \\
\text { 18-China VI-VII }\end{array}$ & North American [6] & $\mathrm{W}$ & - & No changes in designation since the original description [34] \\
\hline 19-West Africa & African palm wine [9]; West Africa [6]; & $\mathrm{D}$ & 2 & \\
\hline 20-Wild Brazil 1-China V & Ecuadorean [9]; Wild Brazil B1 [31] & $\mathrm{w}$ & - & A wild Chinese population also found in Brazil and Ecuador \\
\hline 21-China I & - & $\mathrm{W}$ & - & No changes in designation since the original description [34] \\
\hline 22-Malaysia & - & $\mathrm{w}$ & - & No changes in designation since the original description [6] \\
\hline 23-China III & - & $\mathrm{W}$ & - & No changes in designation since the original description [34] \\
\hline 24-China IV & - & $\mathrm{W}$ & - & No changes in designation since the original description [34] \\
\hline 25-China I & - & $\mathrm{W}$ & - & No changes in designation since the original description [34] \\
\hline 26-China IX & - & $\mathrm{W}$ & - & No changes in designation since the original description [34] \\
\hline 27-China II & - & W & - & No changes in designation since the original description [34] \\
\hline
\end{tabular}




\subsection{The Wine and Olives Clades Harbor Most Type Strains of Former Species}

The largest number of type strains of former Saccharomyces species (23) was assigned to the two clades that congregate wine yeasts (clades 1 and 3, the main Wine clade and the Prise de Mousse clade, respectively). Most of these former type strains (16) were isolated from wine or grapes and two strains are human clinical isolates. The remaining strains were isolated from other fruits (2) or other fermented beverages (2) and one strain has an unknown origin. Previous studies have revealed that an important feature of the Wine clade is the inclusion of strains exhibiting typical genomic markers of a wine strain, but that were isolated in a clinical setting, mostly as human opportunists [7,9]. The two former type strains mentioned above were isolated from similar settings, S. annulatus from a human skin infection in 1929 and S. pulmonalis from the sputum of a tuberculosis patient in 1925, thus confirming that the association between clinical and wine strains is, at least, one century old. Another clinically relevant strain is the reference strain of S. boulardii, widely employed as a probiotic [35]. This synonym of S. cerevisiae was isolated from a lychee in Vietnam but has the main genomic features of a wine strain (Figure 1, Table S1). Therefore, this clade includes both clinical and probiotic strains, which do not have clear discernible features at the genome level.

As already mentioned, all the former type trains isolated from wine investigated here joined clades 1 or 3 . Clade 3 gathers a particular type of wine yeasts relevant for Jerez (Sherry) wines, a type of wine that undergoes an aging process in which an adapted variant of wine yeasts, the flor yeasts, forms a surface biofilm and contributes to the production of specific flavors and aromas [36]. Other genomically similar strains isolated in other countries like Hungary, France or Italy, are particularly resistant to the stresses associated with the advanced stages of fermentation. Probably due to this, commercial strains from this group like the well-known EC1118 [20], proved to be adequate for secondary fermentations in champagne, a process also designated as "prise de mousse" [37] or to re-start stuck fermentations. Four of the six former type strains associated with the prise de mousse clade were isolated in Spain and the remaining two in Armenia and South Africa. The Prise de Mousse clade includes also Georgian wine strains (Figure 1, Table S1) isolated from amphorae [9]. It was recently hypothesized that since the Caucasus is thought to be the birthplace of winemaking, these Georgian isolates could represent the closest relatives of the first domesticated wine strains [9]. However, not only other Georgian strains cluster in the main wine clade and not in the Prise de Mousse clade (Figure 1, Table S1), but, as indicated above, several other strains of different origins and with highly specialized phenotypes are part of the Prise de Mousse clade, that therefore may be derived instead of ancestral.

As previously discussed $[20,25,29,38]$, three genomic regions usually designated as A, B and C, were horizontally transferred from non-Saccharomyces yeasts. They encompass 39 genes potentially relevant for the winemaking process. These regions are well-represented in clades 1 and 3 (Figure 1 ). In line with this, these regions were also more prevalent in the type strains that joined the two wine clades than in type strains that joined other clades.

Six former type strains, mostly isolated from alpechin, the wastewater of olive oil mills, were assigned to a clade distinct, but related to those of wine yeasts (Figure 1, Table 1, Table S1). These strains are S. cerevisiae $\times$ S. paradoxus hybrids [26] and their ecological niche is related to processed olives, including table olives, olive oil and waste water from olive oil mills. The S. cerevisiae subgenomes of these strains (the $S$. paradoxus subgenome was excluded from the analysis) cluster close to the main wine clade (Figure 1), which indicates that the S. cerevisiae ancestor of these hybrids was a wine strain. The species to which these strains were associated with were described between 1957 and 1978 (Table 1) and all had the peculiarity of being unable to assimilate sucrose, an uncommon feature for S. cerevisiae. We confirmed that in all strains of the Olives clade, SUC2 has a premature stop codon, thus explaining the observed phenotype. Another peculiar trait was the capacity to assimilate melibiose, again an uncommon trait for S. cerevisiae. Traditionally, melibiose utilization was regarded as a distinctive marker for the discrimination of $\mathrm{Mel}^{-}$S. cerevisiae wine and top-brewing yeasts from $\mathrm{Mel}^{+}$S. pastorianus, the bottom-brewing yeasts. 


\subsection{The Beer and Bread Clades Contain Multiple Type Strains of Former Species}

S. cerevisiae ale beer yeasts are assigned to two main clades, Clade 11 (Beer 1) that includes most beer types (British, German, wheat beer and Belgian beers) and Clade 5 (Beer 2) that includes low-gravity Saison-type beers (Figure 1). Whereas the main beer group (Beer 1) included only one type strain, in fact the valid type strain of $S$. cerevisiae, which was isolated from a brewery in the Netherlands, the Beer 2 clade included six type strains of former species. Not surprisingly, most type strains in this clade were isolated from beer and the most notable one is the type strain of $S$. diastaticus. This species was described more than 60 years ago as an unusual $S$. cerevisiae-like yeast occurring preferentially as a contaminant in beer fermentations $[39,40]$. The diastase (starch-degrading) ability of $S$. diastaticus is encoded by the chimeric gene STA1 that gives rise to an extra-cellular glucoamylase that allows the conversion of soluble starch and dextrin into fermentable sugars. This leads to an abnormal and undesirable attenuation of beer, corresponding to a specific gravity much lower than what is typical for most beers [41]. Our assignment of the type strain of S. diastaticus to the Beer 2 clade is in line with a recent report indicating the association of diastase-positive strains with this clade [23]. Adding to the elucidation of the contribution of STA1 and its polymorphisms to desirable and undesirable brewing properties and its association mostly with the Beer 2 clade [23], we provide here the phylogenetic placement of seven additional beer-spoiling strains. The phenotypes of these strains were recently characterized [42], and here they were all assigned to the Beer 2 clade (Figure 1). Therefore, this clade, that we rename as "Beer 2-Diastaticus" (Table 2), combines not only strains adequate for beer production, but also an important group of beer-spoilage yeasts. Most notably, these two technologically distinct yeast types are not easy to differentiate at the genome level since brewing strains and spoilage strains appear intermingled in a detailed view of the Beer 2-Diastaticus clade (Figure 2). Interestingly, several of the members of this clade had an excess of heterozygous sites which are likely an indication of ploidy levels higher than 2n (Figure 2), as already shown for Beer 1 strains that are tetraploid [30,43]. However, contrary to Beer 1 and bread yeasts, which invariably have a ploidy higher than 2nd, the Beer 2-Diastaticus clade appears to contain both $2 \mathrm{n}$ and $>2 \mathrm{n}$ strains, which is an uncommon situation among the different populations of $S$. cerevisiae known so far. Our results are in line with previous findings on the strongly variable nature of the diastase activity [23]. Moreover, they support the division of the Beer 2-Diastaticus clade into two subclades, one where the presence of STA1 could not be detected (subclade STA1-negative) and another one positive for STA1. The STA1-negative subclade congregates most of the former type strains found in this group, some of which are associated with brewing or with beer deterioration, but not with diastase activity (Figure 2). The STA1-positive subclade harbors the type strain of $S$. diastaticus and all diastase-positive spoilage strains, together with several brewing strains. A 1162-bp deletion in the promoter of STA1 has been shown to explain a weak diastase activity in STA1-positive strains [23]. This could explain the occurrence on the same lineage of spoiling and beer-production strains. Our survey of this deletion among the genomes of the STA1-positive subclade revealed that all the five strains that exhibited a diastase activity in vitro (Figure S2) had the promoter region intact, whereas the diastase-negative strains for which STA1 was detected (three strains) had the deletion (Figure 2).

The Bread clade contains strains used for bread leavening and is closely related to the beer yeasts of the Beer 1 clade. It includes two former type strains that are clinical isolates, S. cerevisiae var. onychophilus and S. veronae var. osloensis. This suggests that besides the Wine clade, the Bread clade also hosts opportunistic strains. 

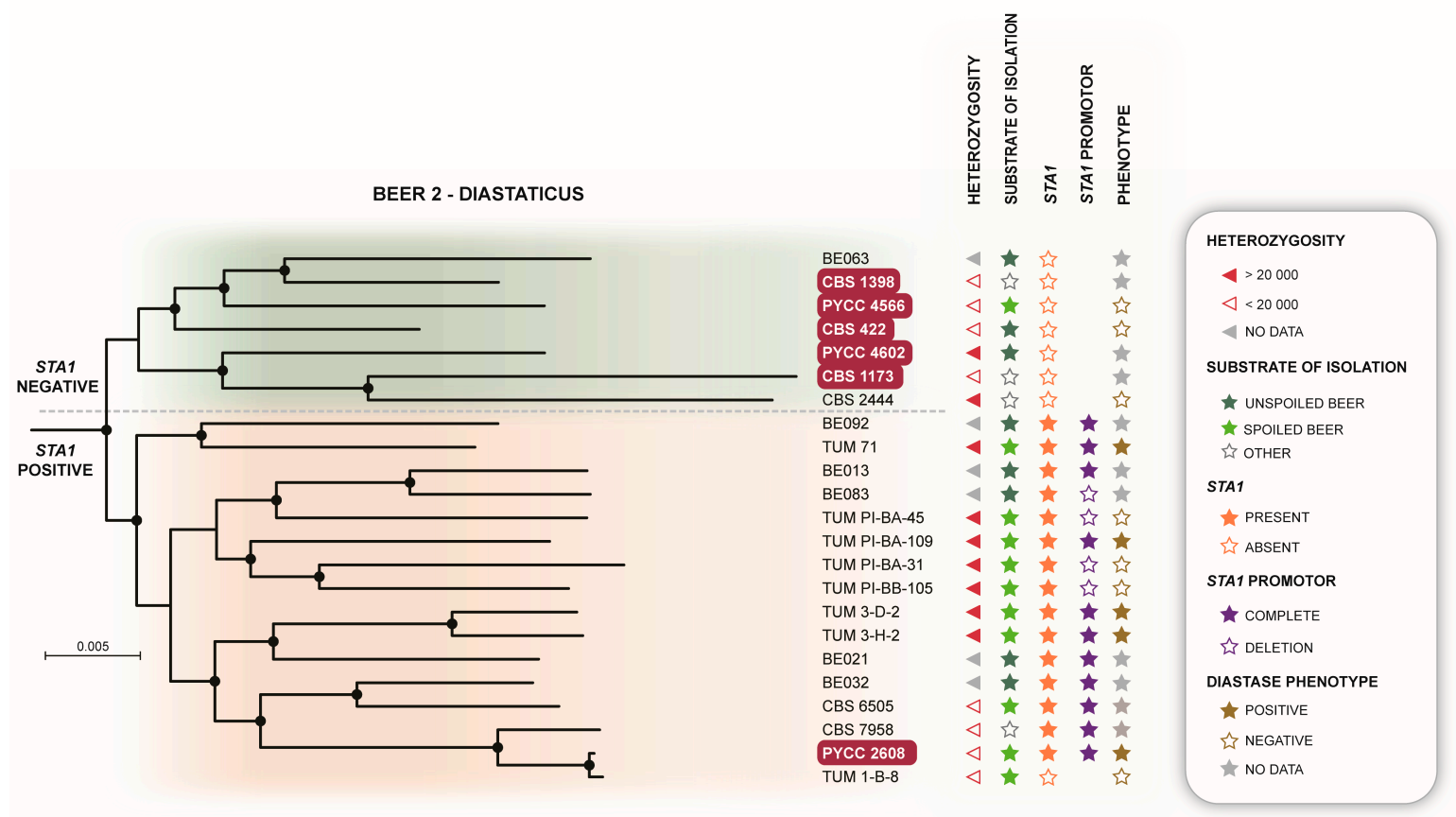

Figure 2. The Beer 2-Diastaticus clade of S. cerevisiae contains STA1-positive and STA1-negative strains. Detail of the main phylogeny showing the phylogenetic relationships within the Beer 2-Diastaticus clade together with relevant genetic and phenotypic attributes.

\subsection{Additional Clades Harboring Type Strains of Former Species}

The remaining six former type strains are placed in three additional clusters, all associated with human-made fermentations (Figure 1). The type strain of S. mangini, found in cheese, was associated with the Dairy clade (Clade 9). This clade was recently described [25] and gathers strains exclusively isolated from dairy products. Three other former type strains belonged to the Sake clade (Clade 15) that gathers strains used to ferment sake in Japan and other cereal-based beverages in other parts of Asia such as Laos, Philippines and Tibet. Not surprisingly, the former type strains of the Sake clade were isolated in China, Japan and Taiwan from sake and other fermentations. Finally, two reference strains clustered in the West Africa clade (Clade 19), and both were isolated from African artisanal fermented beverages, one from ginger beer (S. lindneri) and the other from palm wine (S. chevalieri). For this last species we sequenced strain PYCC 8489, obtained from the NRRL collection (NRRL Y-12633) in 2009. We found its genome sequence to be markedly distinct from that of a supposed copy of NRRL Y-12633, strain Y12 [44,45]. Whereas PYCC 8489 clustered in the West African clade, Y12 belonged to the Sake clade (Figure 1). Given the isolation of $S$. chevalieri from an African fermented beverage, we believe that the sequence of PYCC 8489 represents the correct placement of $S$. chevalieri, whereas Y12 probably does not represent the original African isolate.

\subsection{The Biogeography and Ecology of Wild Populations}

Although the recognition and study of wild populations of S. cerevisiae is of major importance for the detailed understanding of the emergence of domesticates, our knowledge of wild lineages and of their natural biology is much less advanced than that of domesticated populations and their features. In our analysis, we identified 13 wild clades that therefore represent almost half of the total of 27 clades recognized (Figure 1). Our main criteria for identifying a wild clade are the ecological association with a natural niche, sometimes coupled with a well-defined geographical distribution, and the absence of domestication signatures (see below). In two cases, we characterized a clade simultaneously as wild and domesticated. Clade 7 combines wild strains from Brazil, aboriginal human-associated strains from French Guiana and Mexican agave fermentation strains. Clade 16 combines strains directly 
isolated from fruits or tree sap and palm wine strains. In one situation (Clade 14) we characterized a clade as feral, since while its members originate in an arboreal wild environment in China, they possess several typical domestication signatures (Table 2). The wild clades did not include any of the former type strains, thus emphasizing their recent discovery.

Some wild lineages considered here result from the combination of previously recognized lineages. The most striking example is Clade 17, which combines the North America-Japan group [8], the Far East Russia group [9] and the China VI-VII groups [33]. In this case, a wild population predominantly associated with the arboreal niche spans from China to Far East Russia, Japan and North America. Other cases involve the already mentioned Clade 7 in Central and South America and Clade 20 in China, Ecuador and Brazil.

Figure 3 summarizes our current understanding of the biogeography and ecology of wild populations of S. cerevisiae. As already discussed [34], most wild lineages are Chinese or have been originally detected in China. Seven of the 13 wild lineages are exclusively composed of Chinese strains and three additional lineages contain strains from China and from other regions (Figure 3). Moreover, most wild lineages (10 lineages) are associated with arboreal niches, like tree bark, decaying wood and soil underneath trees. In such habitats simple sugars are scarce and therefore the "make-accumulate-consume" (ethanol) ecological strategy of S. cerevisiae [46], may not take place. On the contrary, the Malaysian population (Clade 22), for which a very limited number of clonally related isolates is known, appears to fulfill the anticipated ecological profile of a wild S. cerevisiae population, since it thrives in a sugar-rich environment where ethanol accumulates [47]. Additional wild populations from sugar-rich environments are scarce. The Philippines clade (Clade 16) is a candidate wild population since it contains strains isolated from sap or fruits of palm trees (Table S1). However, several strains in this clade came from different kinds of palm wine, which could suggest a domesticated origin.

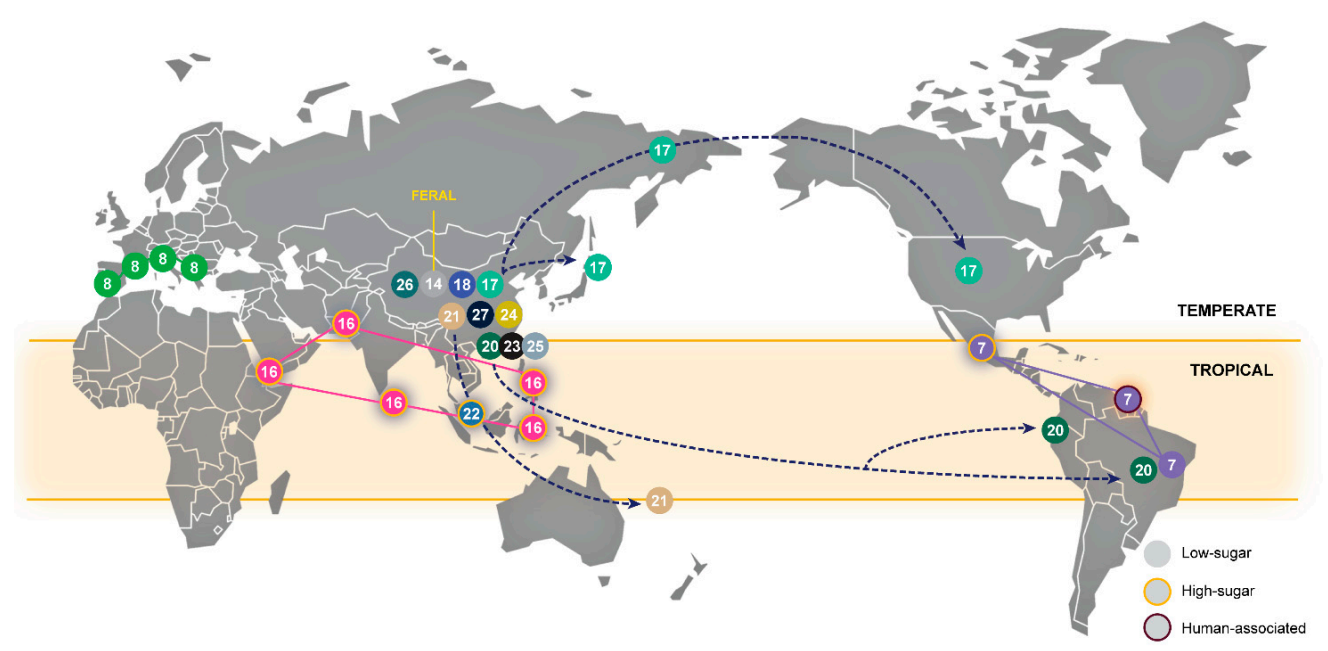

Figure 3. The global biogeography and ecology of wild populations of S. cerevisiae. Populations are numbered and color-coded according to the clades depicted in Figure 1. Circles without outline color correspond to populations associated with low-sugar environments and circles outlined in orange correspond to populations associated with high-sugar environments (in the case of Clade 7, the violet outline color indicates association to the human gut). Possible migration routes are indicated with arrowed dashed lines and population ranges are depicted with solid lines.

The populations found in low-sugar niches appear to occur predominantly in temperate climates and the populations found in high-sugar niches seem to be associated with tropical regions (Figure 3). In China, three wild populations from low-sugar environments were found in the limit of the tropical zone and one of them (Clade 20) is also found in tropical South America (Brazil and Ecuador) (Figure 3). 
The other wild neotropical population (Clade 7) has a complex ecology and is associated with low- and high sugar environments, and also with the human gut (Figure 3).

\subsection{Lifestyle Drives the Fate of Aquaporins}

The loss of function of aquaporins, which are membrane water channels that facilitate the transport of water in and out of the cell, is viewed as a consequence of domestication. Functional aquaporins, encoded by the genes $A Q Y 1$ and $A Q Y 2$, decrease fitness in environments with a high osmolarity caused by an elevated concentration of sugars, like wine must or beer wort, although they contribute to the fitness of wild strains [19]. We observed that all the wild populations associated with the low-sugar arboreal niche (Figure 3) have functional aquaporins (Table S1), while in the Wine, Beer 1, Sake and other domesticated clades the inactivation of aquaporins is the norm [29,43] (Table S1). As discussed elsewhere, the inactivating mutations of $A Q Y 1$ and $A Q Y 2$ are distinct across the various populations [43], which suggests that the loss of function occurred independently and multiple times. The Wine and related secondarily domesticated populations like the Cachaça-Bioethanol population, and also the Dairy population, share the same type of aquaporin gene inactivation, while the Sake and Chinese Fermentations populations exhibit other types of inactivating mutations (Table S1). Moreover, we also observed the inactivation of aquaporins in wild populations associated high-sugar environments, namely the Malaysian and Philippines populations (Table S1). Interestingly in Clade 7, found in the neotropics, the subclade associated with the arboreal niche in Brazil has functional aquaporins whereas the subclades associated with the human gut (French Guiana) and agave fermentations (Mexico) have non-functional aquaporins, whose genes exhibit unique mutations within each subclade (Table S1). Whereas the Malaysian and neotropical populations have distinctive inactivating mutations, not found in any other population, the inactivating mutations in the Philippines population (Clade 16) are the same as those found in the Sake (Clade 15) and Chinese Fermentations (Clade 12), which could indicate a wild-domesticate relationship in the Asian region. Taking into consideration this broader population-level analysis, the argument that aquaporin genes are maintained in two states by balancing selection [19] gets additional support. Moreover, it may be hypothesized that in S. cerevisiae aquaporin gene inactivation occurs whenever a transition to a high-sugar niche occurs, thus including the occurrence of inactivation in wild populations. Therefore, this loss of function may predate human domestication and may be a general and natural response of $S$. cerevisiae to nutritionally rich environments that also occurs, independently and with distinct mutations, in different domesticated lineages.

\subsection{The Natural Reservoirs of RTM1 and BIO1/BIO6}

RTM1 is a subtelomeric gene associated with the locus of sucrose utilization and provides resistance to inhibitory compounds present in molasses [48]. This gene tends to be present in domesticated populations that are grown in molasses or equivalent substrates like beer wort, sugar cane juice or dough, but not in wine yeasts [49]. RTM1 can be viewed as a domestication signature of several clades (Figure 1), and twelve type strains contained this gene, including the valid type strain of S. cerevisiae (Beer 1 clade), five former type strains in the Beer 2-Diastaticus clade, and another six type strains distributed in the Bread, Sake and West Africa clades. The population analysis of RTM1 occurrence shows that it is also present in wild strains, like those of the Philippines (Clade 16), China X (Clade 21) and Malaysia (Clade 22), thus suggesting that domesticated strains may have acquired this gene from natural reservoirs in wild populations. A distinct RTM1 allele was found in strains of the African beer population (Clade 6) and in strains used to ferment Mexican agave (Clade 7). Given the absence of RTM1 homologs in S. paradoxus, it is difficult to access at this stage if these divergent sequences are intraspecific $S$. cerevisiae alleles or if they have a foreign origin.

BIO1 and BIO6 encode enzymes involved in the synthesis of biotin and were considered to have a restricted distribution in S. cerevisiae, being present in strains used in sake fermentation, but absent in wine strains $[43,49,50]$. More recently, BIO1/BIO6 were found to be present in cachaça strains and in wild Brazilian strains [29]. Here, we detected BIO1/BIO6 in 15 of the 27 clades depicted 
in Figure 1. North American S. paradoxus alleles of BIO1/BIO6 appear to have introgressed into American populations. Earlier we reported such alleles in wild Brazilian populations (Clade 7 and Clade 20) and in the Cachaça-Bioethanol group (Clade 4) and also in supposedly European brewing strains of the Beer 2-Diastaticus clade [28]. Here we confirmed and expanded those observations and detected the same type of $S$. paradoxus alleles in additional representatives of the Beer 2-Diastaticus clade and also in all representatives of Clade 7. As discussed above for RTM1, wild populations in Asia (China, Malaysia, Philippines) may have been the original reservoirs of BIO1/BIO6 that later disseminated into domesticated lineages propagated in substrates where biotin is scarce, like sake must.

\subsection{The Complex Distribution of MEL Alleles}

The utilization of melibiose requires the expression of an $\alpha$-galactosidase that hydrolyzes this disaccharide into glucose and galactose. This property is encoded by a set of polymorphic $M E L$ genes [51-53] that are present in S. eubayanus, S. uvarum and S. mikatae, but that are rare in S. cerevisiae and S. paradoxus $[54,55]$. In a series of studies, Naumov and coworkers characterized by genetic mapping 15 genes (MEL1 to MEL15) in S. cerevisiae [55,56], that were found to be distributed in 11 chromosomes in telomeric regions. Together, these studies revealed that wine strains rarely contained this gene, but that strains related to the niche of processed olives could have multiple, highly similar, $M E L$ genes. Another study reported that the Malaysian population (Clade 22) had a good ability to utilize melibiose [22]. This study also revealed a case of melibiose utilization associated with the West African population (Clade 19), but with a distinct evolutionary history since the West African MEL gene appeared to represent an introgression from S. paradoxus.

Our analysis indicated that, although infrequent within the phylogenetic spectrum of S. cerevisiae, $M E L$ occurrence is wider, and its divergence is more complex, than previously anticipated. Of the 27 clades of $S$. cerevisiae depicted in Figure 1, 16 contained MEL alleles. However, the frequency of $\mathrm{MEL}^{+}$genomes in those 16 clades was in most cases lower than $50 \%$ and only in two cases (considering only clades with five or more sequences), the complete fixation of the $M E L$ gene was observed (Olives and Wild Brazil 1-China V). Moreover, five of the 16 clades with MEL genes included former type strains. From the phylogenetic comparison of all $M E L$ sequences detected, we inferred that the native $S$. cerevisiae sequences could be resolved into three alleles, with four additional alleles of uncertain origin (Figure 4A). One allele, "Asian I" (MEL1), was present in genomes assigned to six clades that have in common an Asian origin. This allele was present in several strains of the Chinese Fermentations clade (Clade 12) and of the Sake clade (Clade 15), including the type strain of S. carlsbergensis var. mandschuricus that belongs to this last clade (Figure 4A). This allele was also present in wild populations: Wild Brazil 1-China V (Clade 20), Malaysia (Clade 22), China III (Clade 23) and China I (Clade 25). Another allele, "Asian II", was present in China X (Clade 21). A third allele, "Asian-American", was found in an Asian strain isolated in Sri Lanka and belonging to the Philippines clade (Clade 16) and in two genomes of the Beer 2-Diastaticus clade (Clade 5). These two Asian-American alleles were found in the type strain of S. brasiliensis, a Brazilian brewing strain and in a North American distillery strain. Recombination between Asian II and Asian-American alleles was detected in strain BT3, a Chinese domesticated strain from Clade 12. A similar recombinant allele corresponds to MEL2 found in a strain isolated from dewberries in Russia [56]. A fourth MEL allele, "European", was detected in two wine strains of Clade 1 (Wine) and in all strains of Clade 2 (Olives). In line with the information available in the literature, we confirmed that in wine strains (clades 1 and 3 ) the occurrence of this gene is rare, as we did not detect additional MEL genes in wine strains. The two genomes that had the MEL genes were that of CBS 5635, the type strain of $S$. coreanus and the genome of the commercial wine strain AWRI 796, but in this case the gene had inactivating mutations. Curiously, both strains were isolated in South Africa and another South African strain, from millet beer (Clade 6), also had this allele. A survey in our database of 170 genomes of $S$. cerevisiae wine strains revealed that 10 additional genomes contained MEL genes, but only in two cases the genes were functional. In contrast, all the strains of the Olives clade, i.e., six former type strains, were $\mathrm{MEL}^{+}$. Even in a larger 
strain dataset of more than 20 genomes of this clade related to a previous study [26], we could detect the presence of $M E L$ in all strains, which makes the contrast with $M E L$ scarcity in the wine clades even more striking. This allele corresponded to several MEL genes described previously, from MEL3 to MEL11 [56], which appear to represent a recent event of gene expansion in S. cerevisiae associated with domestication. All strains of the Olives clade had four or more MEL copies, with the highest copy numbers being recorded for S. hienipiensis (10) and S. norbensis (11). Interestingly, the European allele was also found in three strains of S. paradoxus (Figure 4A). These strains were isolated in Greece and belong to the European population of that species. The S. cerevisiae and S. paradoxus sequences of the European allele are almost identical, which suggests a case of introgression between these two species, but whose donor and recipient cannot be unequivocally identified at present.

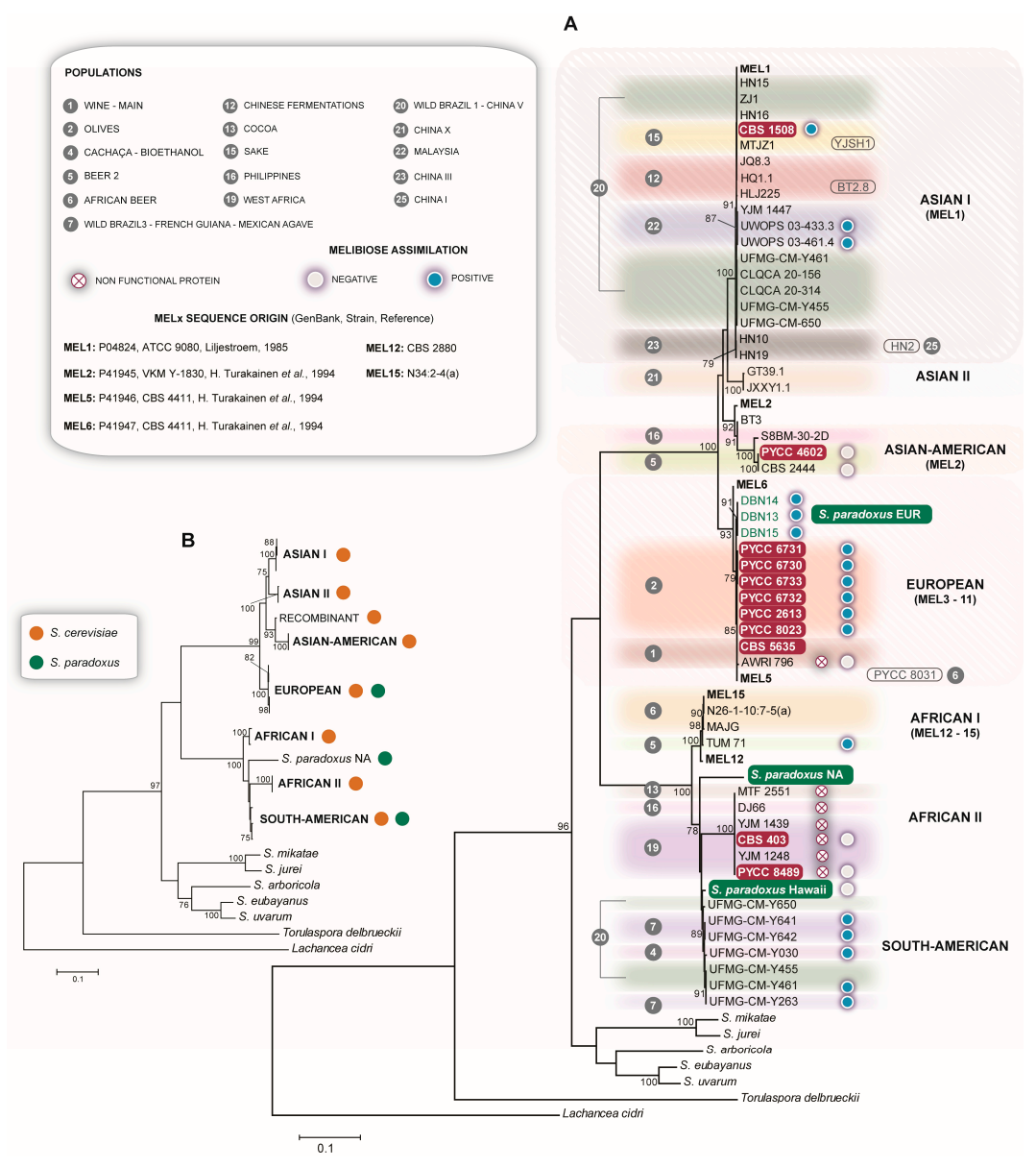

Figure 4. Phylogenetic analysis of $M E L$ alleles of S. cerevisiae. (A) Phylogenetic overview of $M E L$ alleles from 16 populations of $S$. cerevisiae. For comparison, $M E L$ sequences from other Saccharomyces species were included together with S. cerevisiae MEL alleles (MEL1, MEL2, MEL5, MEL6, MEL12 and MEL15) retrieved from the literature and from the NCBI database (MEL12 and MEL15 were retrieved directly from genomic assemblies). For $S$. paradoxus, sequences from representatives of the European (EUR), North American (NA) and Hawaiian populations were added. Incomplete sequences that could be assigned to an allelic group, but that were not used in the final phylogeny are indicated next to the tree in a rounded rectangle. The former type strains of $S$. cerevisiae are indicated in red rectangles; (B) simplified phylogeny of MEL alleles in the genus Saccharomyces. The two phylogenetic trees were constructed using the Maximum Likelihood method and the Tamura 3-parameter model. Bootstrap values $>75 \%$ are indicated (1000 replicates).

A fifth allele (African I), is found mostly in S. cerevisiae strains isolated in Africa (Clade 6, African beer) and corresponds to MEL12 to MEL15 [51]. A similar allele (African II) is also present 
in African strains, mostly of Clade 19 (West Africa), but is a pseudogene, as previously reported [22]. The type strains of $S$. chevalieri and $S$. lindneri contain this allele. The last allele (South American) is present in wild Brazilian strains (clades 7 and 20) and in Brazilian domesticated strains used for sugar cane (cachaça) fermentations (Clade 4). Interestingly, Clade 20 that combines wild Chinese and wild Brazilian and Ecuadorean strains, contains the Asian I allele, present in all strains and the South American allele that co-occurs with the Asian I allele in Brazilian strains.

The African and South American alleles are not only considerably divergent from the Asian and European ones, but also share a phylogenetic proximity with S. paradoxus MEL genes found in representatives of the North American and Hawaiian population of this species (Figure 4A). Again, an introgression involving S. cerevisiae and S. paradoxus can be hypothesized, but the donor and the recipient species cannot be identified at present. The frequency of MEL genes in S. paradoxus appears to be low. Among the European strains, we surveyed 40 genomes and only in three cases did we found these genes. For the other populations we detected two positive cases among 30 surveyed genomes (Table S2).

We tested strains harboring distinct alleles for the ability to grow on melibiose and observed some cases of absence of growth on this compound (Figure 4A and Figure S3). As expected, the inactivating mutations in the European allele of wine strains and in the African II allele resulted in a MEL- phenotype. Moreover, the strains with the Asian-American alleles and the North American and Hawaiian strains of S. paradoxus were also incapable of growing on melibiose in spite of having apparently functional genes.

A simplified phylogeny of the MEL gene for the genus Saccharomyces is presented in Figure 4B. Given the suspected introgressions to or from S. paradoxus, the boundaries between S. cerevisiae and S. paradoxus are not easily discernible. Since the average genome divergence between S. cerevisiae and S. paradoxus is $10 \%$, the approximate $10 \%$ pairwise sequence divergence observed between the Asian I, II and Asian-American and the European allele could represent the above mentioned species-level divergence (Figure 4B). In this scenario, Asian I, II and Asian-American would represent the S. cerevisiae native allele and European would represent the S. paradoxus allele. Consequently, the European alleles found in S. cerevisiae wine and olives strains would represent an introgression from S. paradoxus. However, the origin of the remaining African and South American alleles, which are $20 \%$ divergent from the Asian I allele, is puzzling and can only be explained by an introgression from an unknown Saccharomyces species that is phylogenetically more related to S. cerevisiae and S. paradoxus than any currently known Saccharomyces species. An alternative explanation is to view the Asian I, II, Asian-American and the European alleles as native to S. cerevisiae, in spite of their remarkable divergence, and the African-South American ones as native to S. paradoxus. In this scenario, $M E L$ divergence between $S$. cerevisiae and $S$. paradoxus is approximately double the average genomic divergence. This hypothesis also implies that the European allele was introgressed from S. cerevisiae into S. paradoxus and the African-South American alleles were introgressed from S. paradoxus into S. cerevisiae.

\section{Discussion}

In this study, we attempted to compare the diversity of a group of 45 type strains of species now viewed as $S$. cerevisiae synonyms, while simultaneously reassessing the population landscape of the species at a global scale. Under the lens of genomics, this group of former type strains represents a valuable historical record of diversity, ecology and biogeography that spans from 1870 (S. ellipsoideus) to 1984 (S. boulardii). When this diversity is superimposed on the global population diversity of S. cerevisiae, former type strains map reasonably well on the known domesticated populations but are absent in wild populations. This is an eloquent illustration of the roots of our biased understanding of $S$. cerevisiae primarily as a utility in wine, beer and bread production (among much other fermented products), rather than as a microbe shaped by its natural history. Another interesting observation is the strong redundancy of old species delimitations, based mostly on strains that belong to the Wine and Olives populations. A minor redundancy is also present in the Beer 2-Diastaticus, Bread, West Africa and Sake clades, but not in the Dairy and Beer 1 population. Our analysis also clarifies the status of historically and technologically relevant Saccharomyces species names for users in the fermentation industry. 
Various population genomics studies of $S$. cerevisiae have been published in recent years and consequently distinct designations have been used to name the same population. Such lack of consistency, together with incomplete sampling, strong redundancy of certain domesticated lineages or the improper use of the "wild" descriptor, call for the need of an informed debate. Population VIII from China (Clade 14) provides a striking example of the difficulties in recognizing a wild lineage. Undisputedly considered as "wild", it was even used as evidence supporting the East Asian origin of all domesticated S. cerevisiae strains since it carries duplicated genes involved in maltose metabolism, thus appearing as the direct link between wild and domesticated lineages [33,57]. However, $M A L$ expansion can be viewed as a domestication footprint and in fact this population has additional signatures of domestication like a type of inactivation mutation of $A Q Y 1$ and the presence of region B (Table S1) that are typical of wine strains. Consequently, China VIII must be regarded as a feral population, not a wild one.

A recent study included a comprehensive genomic survey of $S$. cerevisiae that involved 362 strains from the Wine clade [9]. Following earlier publications [6], this clade was referred to as "Wine/European" in spite of the well-recognized global distribution of wine strains, not only from Europe, but also from North and South America, South Africa and Oceania, the enrichment in European strains in this clade being simply the likely consequence of an historical sampling bias in Europe. Moreover, the truly European population corresponds to a wild South European population, closely related, but phylogenetically distinct from the wine yeasts [58]. This is so far the only population to which the epithet "European" can be appropriately applied since all members of this population were found exclusively in Europe. In addition. the claim that wild strains represent $16 \%$ of the isolates of the Wine clade [9], needs to be verified since the finding of a strain exhibiting key genomic features of the Wine clade, but isolated from soil or another non-wine substrate, does not warrant the classification as wild, as feral may be a more adequate descriptor, thus avoiding confusion with truly wild strains.

Recently, the genomes of 266 wild and domesticated Asian isolates were sequenced and it was proposed that China and Far East Asia are the center of domestication of S. cerevisiae [33]. In another recent study, 1011 genomes were analyzed and although the "out-of-China" model for wild populations of $S$. cerevisiae was supported, it was suggested that several independent domestication events explain the emergence of domesticated populations [9]. Here, we combined key representative sequences of both studies and although most of the phylogenetic structure of $S$. cerevisiae from previous studies could be recovered, a supposedly distinctive position of Asian domesticated lineages, compatible with an initial domestication in China from which all other domestications derive, could not be confirmed. Instead, most Chinese domesticated strains appear closely related and were gathered in a new clade (Clade 12, Chinese fermentations) that is nevertheless distinct from the Sake clade (Clade 15), a key group in most population studies, but that was not adequately represented in the study of Asian strains.

By combining genome sequences obtained in recent studies by other authors and those sequenced by us, we could observe that some of the Chinese wild populations, which globally represent the most diverse assemblage of populations in the species, have members in other regions, including other continents. This illustrates not only the broad range of the distribution of some wild populations, but also their ability to migrate over thousands of kilometers, for example, across the Indian or Pacific oceans. The mechanisms and consequences of such long range dispersal still await a formal study. Another relevant aspect is the coexistence in sympatry of distinct wild lineages without apparent relevant genetic contact. Again, the drivers for such long-term sympatric coexistence of different genetic lineages remain unknown.

If our current understanding of $S$. cerevisiae populations is taken into consideration, a wide diversity of lifestyles appears as the hallmark of this species. Such diversity is still remarkable when only wild populations are considered since arboreal (low-sugar) and sap-fruit-nectar (high-sugar) lifestyles are known. This has not been observed in S. cerevisiae closest relative, S. paradoxus, in spite of their close genetic resemblance and even sympatry of these two species in certain temperate regions [59,60]. We speculate that the better adaptation of $S$. cerevisiae to higher temperatures, reflected in its biogeography [60], allowed the colonization of tropical regions and the consequent transition to high-sugar niches. In several ways, 
the transitions promoted by humans during the fermentation of beverages or foodstuffs, mimic the transitions in nature from low-sugar to high-sugar niches. Independent inactivation of aquaporin genes in the wild and in the winery are an indication of such plasticity.

Recently, we proposed a domestication model with transitions from a primarily domesticated state, exemplified by wine yeasts, to a secondarily domesticated state, exemplified by cachaça-bioethanol yeasts [29]. The regions A, B and C, likely acquired first by wine strains [20], are also present (especially region B) in secondarily domesticated lineages that derive from wine yeasts like Bread, Beer 2-Diastaticus and Cachaça-Bioethanol (Figure 1). In sharp contrast, these regions are absent in wild lineages.

Contrary to regions A, B and C that were acquired solely during domestication, other traits like aquaporin inactivation, the presence of the RTM1 cluster or the presence of the BIO1/BIO6 genes appear to have predated domestication. We observed that such traits already occur in wild populations, especially in Asian ones. Therefore, the presence of the RTM1 cluster or the BIO1/BIO6 genes in certain domesticated populations may originate in the wild genetic stock of the species. Likewise, the propensity for aquaporin inactivation observed in domesticated populations may recapitulate a natural phenomenon that occurs in wild populations. For MEL alleles and in spite of their still unclear evolutionary history, which also involves S. paradoxus, their origin in S. cerevisiae is again centered in Asia and in wild populations.

Supplementary Materials: The following are available online at http://www.mdpi.com/2076-2607/8/6/903/s1, Figure S1: Unrooted phylogeny S. cerevisiae genomes representing the known diversity of the species, Figure S2: ${ }^{\circ}$ Brix measurements during growth in beer wort for 15 days at $25{ }^{\circ} \mathrm{C}$, Figure S3: Growth curves on $1 \%(w / v)$ melibiose medium supplemented with yeast nitrogen base and incubated at $25^{\circ} \mathrm{C}$ for three days, Table S1: Strains and genomes used in this study and relevant information pertaining to them, Table S2: Presence (+) or absence (-) of the $M E L$ gene in the genomes of $S$. paradoxus from different populations.

Author Contributions: Conceptualization, J.P.S.; methodology, A.P., M.H.; software, P.H.B.; investigation, A.P., M.H., P.H.B.; resources, J.P.S.; data curation, A.P.; writing-J.P.S.; writing-review and editing, A.P., M.H., J.P.S.; visualization, A.P.; supervision, J.P.S.; project administration, J.P.S.; funding acquisition, J.P.S. All authors have read and agreed to the published version of the manuscript.

Funding: This research was funded by Fundação para a Ciência e a Tecnologia (Portugal) Grant Number PTDC/BIA-MIC/30785/2017 and UIDB/04378/2020. A.P. was funded by Grant Number SFRH/BD/136462/2018.

Acknowledgments: We thank Paula Gonçalves for critical comments on the manuscript. We thank the reviewers for their helpful comments that contributed to improve the readability of the text.

Conflicts of Interest: The authors declare no conflicts of interest. The funders had no role in the design of the study; in the collection, analyses or interpretation of data; in the writing of the manuscript or in the decision to publish the results.

\section{References}

1. Meyen, J. Jahresbericht uber die Resultate der Arbeiten im Felde der physiologischen Botanik von dem Jahre 1837. Arch. Naturgesch. 1838, 4, 1-186.

2. Stelling-Dekker, N.M. Die sporogenen Hefen. Verh. K. Ned. Akad. Wetensch. Afd. Natuurk. Sect. II 1931, 28, 1-547.

3. Lodder, J; Kreger van Rij, N. The Yeasts, A Taxonomic Study; North-Holland: Amsterdam, The Netherlands, 1952.

4. Van der Walt, J.P. Saccharomyces (Meyen) emend. Reess. In The Yeasts, A Taxonomic Study; Lodder, J., Ed.; North-Holland: Amsterdam, The Netherlands, 1970; pp. 555-718.

5. Yarrow, D. Saccharomyces Meyen ex Reess. In The Yeasts, A Taxonomic Study; Kreger van Rig, N., Ed.; Elsevier: Amsterdam, The Netherlands, 1984; pp. 379-395.

6. Liti, G.; Carter, D.M.; Moses, A.M.; Warringer, J.; Parts, L.; James, S.A.; Davey, R.P.; Roberts, I.N.; Burt, A.; Koufopanou, V.; et al. Population genomics of domestic and wild yeasts. Nature 2009, 458, 337-341. [CrossRef] [PubMed]

7. Strope, P.K.; Skelly, D.A.; Kozmin, S.G.; Mahadevan, G.; Stone, E.A.; Magwene, P.M.; Dietrich, F.S.; McCusker, J.H. The 100-genomes strains, an S. cerevisiae resource that illuminates its natural phenotypic and genotypic variation and emergence as an opportunistic pathogen. Genome Res. 2015, 25, 762-774. [CrossRef] 
8. Almeida, P.; Barbosa, R.; Zalar, P.; Imanishi, Y.; Shimizu, K.; Turchetti, B.; Legras, J.-L.; Serra, M.; Dequin, S.; Couloux, A.; et al. A population genomics insight into the Mediterranean origins of wine yeast domestication. Mol. Ecol. 2015, 24, 5412-5427. [CrossRef]

9. Peter, J.; de Chiara, M.; Friedrich, A.; Yue, J.-X.; Pflieger, D.; Bergström, A.; Sigwalt, A.; Barré, B.P.; Freel, K.; Llored, A.; et al. Genome evolution across 1,011 Saccharomyces cerevisiae isolates. Nature 2018, 556, 339-344. [CrossRef]

10. Scannell, D.R.; Zill, O.; Rokas, A.; Payen, C.; Dunham, M.J.; Eisen, M.B.; Rine, J.; Johnston, M.; Hittinger, C.T. The awesome power of yeast evolutionary genetics: new genome sequences and strain resources for the Saccharomyces sensu stricto genus. G3 Genes/Genomes/Genetics 2011, 1, 11-25. [CrossRef]

11. Liti, G.; Ba, A.N.N.; Blythe, M.J.; Müller, C.A.; Bergström, A.; Cubillos, F.A.; Dafhnis-Calas, F.; Khoshraftar, S.; Malla, S.; Mehta, N.; et al. High quality de novo sequencing and assembly of the Saccharomyces arboricolus genome. BMC Genom. 2013, 14, 69. [CrossRef]

12. Borneman, A.R.; Forgan, A.H.; Kolouchova, R.; Fraser, J.A.; Schmidt, S.A. Whole genome comparison reveals high levels of inbreeding and strain redundancy across the spectrum of commercial wine strains of Saccharomyces cerevisiae. G3 Genes/Genomes/Genetics 2016, 6, 957-971. [CrossRef]

13. Li, H.; Handsaker, B.; Wysoker, A.; Fennell, T.; Ruan, J.; Homer, N.; Marth, G.; Abecasis, G.R.; Durbin, R.; 1000 Genome Project Data Processing Subgroup. The Sequence Alignment/Map format and SAMtools. Bioinformatics 2009, 25, 2078-2079. [CrossRef]

14. Almeida, P.; Gonçalves, C.; Teixeira, S.; Libkind, D.; Bontrager, M.; Masneuf-Pomarede, I.; Albertin, W.; Durrens, P.; Sherman, D.J.; Marullo, P.; et al. A Gondwanan imprint on global diversity and domestication of wine and cider yeast Saccharomyces uvarum. Nat. Commun. 2014, 5, 4044. [CrossRef]

15. Nguyen, L.-T.; Schmidt, H.A.; von Haeseler, A.; Minh, B.Q. IQ-TREE: A Fast and effective stochastic algorithm for estimating Maximum-Likelihood phylogenies. Mol. Biol. Evol. 2014, 32, 268-274. [CrossRef] [PubMed]

16. Hoang, D.T.; Chernomor, O.; von Haeseler, A.; Minh, B.Q.; Vinh, L.S. UFBoot2: Improving the ultrafast bootstrap approximation. Mol. Biol. Evol. 2018, 35, 518-522. [CrossRef] [PubMed]

17. Letunic, I.; Bork, P. Interactive tree of life (iTOL) v3: An online tool for the display and annotation of phylogenetic and other trees. Nucleic Acids Res. 2016, 44, 242-245. [CrossRef] [PubMed]

18. Kumar, S.; Stecher, G.; Tamura, K. MEGA7: Molecular evolutionary genetics analysis version 7.0 for bigger datasets. Mol. Boil. Evol. 2016, 33, 1870-1874. [CrossRef] [PubMed]

19. Will, J.L.; Kim, H.S.; Clarke, J.; Painter, J.C.; Fay, J.C.; Gasch, A.P. Incipient balancing selection through adaptive loss of aquaporins in natural Saccharomyces cerevisiae populations. PLoS Genet. 2010, 6, e1000893. [CrossRef] [PubMed]

20. Novo, M.; Bigey, F.; Beyne, E.; Galeote, V.; Gavory, F.; Mallet, S.; Cambon, B.; Legras, J.-L.; Wincker, P.; Casaregola, S.; et al. Eukaryote-to-eukaryote gene transfer events revealed by the genome sequence of the wine yeast Saccharomyces cerevisiae EC1118. Proc. Natl. Acad. Sci. USA 2009, 106, 16333-16338. [CrossRef]

21. Nijkamp, J.; Broek, M.V.D.; Datema, E.; de Kok, S.; Bosman, L.; Luttik, M.A.; Daran-Lapujade, P.; Vongsangnak, W.; Nielsen, J.; Heijne, W.H.; et al. De novo sequencing, assembly and analysis of the genome of the laboratory strain Saccharomyces cerevisiae CEN.PK113-7D, a model for modern industrial biotechnology. Microb. Cell Factories 2012, 11, 36. [CrossRef]

22. Warringer, J.; Zörgö, E.; Cubillos, F.A.; Zia, A.; Gjuvsland, A.B.; Simpson, J.T.; Forsmark, A.; Durbin, R.; Omholt, S.W.; Louis, E.; et al. Trait variation in yeast is defined by population history. PLoS Genet. 2011, 7, e1002111. [CrossRef]

23. Krogerus, K.; Magalhães, F.; Kuivanen, J.; Gibson, B. A deletion in the STA1 promoter determines maltotriose and starch utilization in STA1+ Saccharomyces cerevisiae strains. Appl. Microbiol. Biotechnol. 2019, 103, 7597-7615. [CrossRef]

24. Yue, J.-X.; Li, J.; Aigrain, L.; Hallin, J.; Persson, K.; Oliver, K.; Bergström, A.; Coupland, P.; Warringer, J.; Lagomarsino, M.C.; et al. Contrasting evolutionary genome dynamics between domesticated and wild yeasts. Nat. Genet. 2017, 49, 913-924. [CrossRef] [PubMed]

25. Legras, J.-L.; Galeote, V.; Bigey, F.; Camarasa, C.; Marsit, S.; Nidelet, T.; Sanchez, I.; Couloux, A.; Guy, J.; Franco-Duarte, R.; et al. Adaptation of $S$. cerevisiae to fermented food environments reveals remarkable genome plasticity and the footprints of domestication. Mol. Biol. Evol. 2018, 35, 1712-1727. [CrossRef] [PubMed]

26. Pontes, A.; Čadež, N.; Gonçalves, P.; Sampaio, J.P. A quasi-domesticate relic hybrid population of Saccharomyces cerevisiae $\times$ S. paradoxus adapted to olive brine. Front. Genet. 2019, 10, 449. [CrossRef] [PubMed] 
27. Cromie, G.A.; Hyma, K.E.; Ludlow, C.L.; Garmendia-Torres, C.; Gilbert, T.L.; May, P.; Huang, A.A.; Dudley, A.M.; Fay, J.C. Genomic sequence diversity and population structure of Saccharomyces cerevisiae assessed by RAD-seq. G3 (Bethesda) 2013, 3, 2163-2171. [CrossRef]

28. Legras, J.L.; Merdinoglu, D.; Cornuet, J.M.; Karst, F. Bread, beer and wine: Saccharomyces cerevisiae diversity reflects human history. Mol. Ecol. 2007, 16, 2091-2102. [CrossRef] [PubMed]

29. Barbosa, R.; Pontes, A.; Santos, R.O.; Montandon, G.G.; de Ponzzes-Gomes, C.M.; Morais, P.B.; Gonçalves, P.; Rosa, C.A.; Sampaio, J.P. Multiple rounds of artificial selection promote microbe secondary domestication - the case of cachaça yeasts. Genome Biol. Evol. 2018, 10, 1939-1955. [CrossRef] [PubMed]

30. Gallone, B.; Steensels, J.; Prahl, T.; Soriaga, L.; Saels, V.; Herrera-Malaver, B.; Merlevede, A.; Roncoroni, M.; Voordeckers, K.; Miraglia, L.; et al. Domestication and divergence of Saccharomyces cerevisiae beer yeasts. Cell 2016, 166, 1397-1410. [CrossRef]

31. Barbosa, R.; Almeida, P.; Safar, S.V.B.; Santos, R.O.; Morais, P.B.; Nielly-Thibault, L.; Leducq, J.-B.; Landry, C.R.; Gonçalves, P.; Rosa, C.A.; et al. Evidence of natural hybridization in Brazilian wild lineages of Saccharomyces cerevisiae. Genome Biol. Evol. 2016, 8, 317-329. [CrossRef]

32. Angebault, C.; Djossou, F.; Abélanet, S.; Permal, E.; Soltana, M.B.; Diancourt, L.; Bouchier, C.; Woerther, P.L.; Catzeflis, F.; Andremont, A.; et al. Candida albicans is not always the preferential yeast colonizing humans: a study inwayampi amerindians. J. Infect. Dis. 2013, 208, 1705-1716. [CrossRef]

33. Duan, S.; Han, P.-J.; Wang, Q.-M.; Liu, W.-Q.; Shi, J.-Y.; Li, K.; Zhang, X.-L.; Bai, F.-Y. The origin and adaptive evolution of domesticated populations of yeast from Far East Asia. Nat. Commun. 2018, 9, 2690. [CrossRef]

34. Wang, Q.-M.; Liu, W.-Q.; Liti, G.; Wang, S.-A.; Bai, F.-Y. Surprisingly diverged populations of Saccharomyces cerevisiae in natural environments remote from human activity. Mol. Ecol. 2012, 21, 5404-5417. [CrossRef] [PubMed]

35. Zanello, G.; Meurens, F.; Berri, M.; Salmon, H. Saccharomyces boulardii effects on gastrointestinal diseases. Curr. Issues Mol. Biol. 2008, 11, 47-58. [PubMed]

36. Legras, J.-L.; Erny, C.; Charpentier, C. Population structure and comparative genome hybridization of European flor yeast reveal a unique group of Sacharomyces cerevisiae strains with few gene duplications in their genome. PLoS ONE 2014, 9, e108089. [CrossRef] [PubMed]

37. Torresi, S.; Frangipane, M.T.; Anelli, G. Biotechnologies in sparkling wine production. Interesting approaches for quality improvement: A review. Food Chem. 2011, 129, 1232-1241. [CrossRef]

38. Marsit, S.; Leducq, J.-B.; Durand, E.; Marchant, A.; Filteau, M.; Landry, C.R. Evolutionary biology through the lens of budding yeast comparative genomics. Nat. Rev. Genet. 2017, 18, 581-598. [CrossRef]

39. Andrews, B.J.; Gilliland, R.B. Super-attenuation of beer: A study of three organisms capable of causing abnormal attenuations. J. Inst. Brew. 1952, 58, 189-196. [CrossRef]

40. Van der Walt, J.P. Saccharomyces vafer and S. inconspicuus spp.n. Antonie Leeuwenhoek 1965, 31, 187-192. [CrossRef]

41. Gilliland, R.B. Sacchatomyces diastaticus—A starch-fermenting yeast. J. Inst. Brew. 1966, 72, 271-275. [CrossRef]

42. Meier-Dörnberg, T.; Kory, O.I.; Jacob, F.; Michel, M.; Hutzler, M. Saccharomyces cerevisiae variety diastaticus friend or foe?-Spoilage potential and brewing ability of different Saccharomyces cerevisiae variety diastaticus yeast isolates by genetic, phenotypic and physiological characterization. FEMS Yeast Res. 2018, 18. [CrossRef]

43. Gonçalves, M.; Pontes, A.; Almeida, P.; Barbosa, R.; Serra, M.; Libkind, D.; Hutzler, M.; Gonçalves, P.; Sampaio, J. Distinct domestication trajectories in top-fermenting beer yeasts and wine yeasts. Curr. Biol. 2016, 26, 2750-2761. [CrossRef]

44. Fay, J.C.; Benavides, J.A. Evidence for domesticated and wild populations of Saccharomyces cerevisiae. PLoS Genet. 2005, 1, e5. [CrossRef] [PubMed]

45. Bergström, A.; Simpson, J.T.; Salinas, F.; Barré, B.P.; Parts, L.; Zia, A.; Ba, A.N.N.; Moses, A.M.; Louis, E.; Mustonen, V.; et al. A high-definition view of functional genetic variation from natural yeast genomes. Mol. Biol. Evol. 2014, 31, 872-888. [CrossRef] [PubMed]

46. Piškur, J.; Rozpedowska, E.; Polakova, S.; Merico, A.; Compagno, C. How did Saccharomyces evolve to become a good brewer? Trends Genet. 2006, 22, 183-186. [CrossRef] [PubMed]

47. Wiens, F.; Zitzmann, A.; Lachance, M.-A.; Yegles, M.; Pragst, F.; Wurst, F.M.; Von Holst, D.; Guan, S.L.; Spanagel, R. Chronic intake of fermented floral nectar by wild treeshrews. Proc. Natl. Acad. Sci. USA 2008, 105, 10426-10431. [CrossRef] [PubMed]

48. Ness, F.; Aigle, M. Rtm1: A member of a new family of telomeric repeated genes in yeast. Genetics 1995, 140, 945-956. 
49. Borneman, A.R.; Pretorius, I.S. Genomic Insights into the Saccharomyces sensu stricto complex. Genetics 2015, 199, 281-291. [CrossRef] [PubMed]

50. Hall, C.; Dietrich, F.S. The reacquisition of biotin prototrophy in Saccharomyces cerevisiae involved horizontal gene transfer, gene duplication and gene clustering. Genetics 2007, 177, 2293-2307. [CrossRef]

51. Naumov, G.; Turakainen, H.; Naumova, E.; Aho, S.; Korhola, M. A new family of polymorphic genes in Saccharomyces cerevisiae: $\alpha$-galactosidase genes MEL1-MEL7. Mol. Genet. Genom. 1990, 224, 119-128. [CrossRef]

52. Naumov, G.; Naumova, E.; Turakainen, H.; Suominen, P.; Korhola, M. Polymeric genes MEL8, MEL9 and MEL10 new members of $\alpha$-galactosidase gene family in Saccharomyces cerevisiae. Curr. Genet. 1991, 20, 269-276. [CrossRef]

53. Turakainen, H.; Aho, S.; Korhola, M. MEL gene polymorphism in the genus Saccharomyces. Appl. Environ. Microbiol. 1993, 59, 2622-2630. [CrossRef]

54. Naumova, E.S.; Serpova, E.V.; Korshunova, I.V.; Naumov, G.I. Molecular polymorphism of $\alpha$-galactosidase MEL genes of Saccharomyces yeasts. Microbiology 2011, 80, 502-513. [CrossRef]

55. Naumov, G.I.; Naumova, E.S.; Korshunova, I.V.; Jakobsen, M. Yeast comparative genetics: a new MEL15 $\alpha$-Galactosidase gene of Saccharomyces cerevisiae. Russ. J. Genet. 2002, 38, 1127-1132. [CrossRef]

56. Naumova, E.S.; Korshunova, I.V.; Naumov, G.I. Molecular analysis of alpha-galactosidase MEL genes from Saccharomyces sensu stricto. Mol. Biol. 2003, 37, 699-703. [CrossRef]

57. Fay, J.C.; Liu, P.; Ong, G.T.; Dunham, M.J.; Cromie, G.A.; Jeffery, E.W.; Ludlow, C.L.; Dudley, A.M. A polyploid admixed origin of beer yeasts derived from European and Asian wine populations. PLoS Biol. 2019, 17, e3000147. [CrossRef] [PubMed]

58. Sampaio, J.P.; Gonçalves, P. Biogeography and ecology of the genus Saccharomyces. In Yeasts in Natural Ecosystems: Ecology; Buzzini, P., Lachance, M.-A., Yurkov, A., Eds.; Springer International Publishing: Cham, Switzerland, 2017; pp. 131-153.

59. Sampaio, J.; Gonçalves, P. Natural populations of Saccharomyces kudriavzevii in Portugal are associated with oak bark and are sympatric with S. cerevisiae and S. paradoxus. Appl. Environ. Microbiol. 2008, 74, 2144-2152. [CrossRef] [PubMed]

60. Robinson, H.A.; Pinharanda, A.; Bensasson, D. Summer temperature can predict the distribution of wild yeast populations. Ecol. Evol. 2016, 6, 1236-1250. [CrossRef]

(C) 2020 by the authors. Licensee MDPI, Basel, Switzerland. This article is an open access article distributed under the terms and conditions of the Creative Commons Attribution (CC BY) license (http://creativecommons.org/licenses/by/4.0/). 